\title{
Size Distribution and Estimated Carcinogenic Potential of Particulate Polycyclic Aromatic Hydrocarbons Collected at a Downtown Site in Kumamoto, Japan, in Spring
}

\author{
Hezhe Ji, Daizhou Zhang, ${ }^{*}$ and Ryota Shinohara \\ Faculty of Environmental and Symbiotic Sciences, Prefectural University of Kumamoto, Tsukide 3-1-100, Kumamoto 862-8502, Japan
}

(Received July 6, 2007; Accepted September 14, 2007; Published online October 3, 2007)

\begin{abstract}
Atmospheric particles at a roadside site in the downtown area of Kumamoto, Japan, were collected in the spring of 2006. A cascade impactor was used to fractionate the particles into nine size ranges: > 11.0, 11.0-7.0, 7.0-4.7, $4.7-3.3,3.3-2.1,2.1-1.1,1.1-0.65,0.65-0.43$, and $<0.43 \mu \mathrm{m}$. Ten polycyclic aromatic hydrocarbons (PAHs) with 4, 5 , and 6 rings [fluoranthene (Flu), pyrene (Pyr), benz(a)anthracene (BaA), chrysene (Chry), benzo(b)fluoranthene $(\mathrm{BbF})$, benzo(k)fluoranthene $(\mathrm{BkF})$, benzo(a)pyrene $(\mathrm{BaP})$, benzo(ghi)perylene (BghiP), dibenz(a,h)anthracene (DahA), indeno(1,2,3-cd)pyrene (IcdP)] in the size ranges were expressed and investigated in terms of their total and individual concentrations and the equivalents of benzo(a)pyrene $(B a P E)$ upon their relative carcinogenic potential. The correspondence of PAHs to particle size, PAHs tending to accumulate in small size ranges, was confirmed. The mass of PAHs in the size range $<2.1 \mu \mathrm{m}$ averaged 4-fold more than that in the range $>2.1 \mu \mathrm{m}$. The PAHs with 5 and 6 rings predominated in the total mass of the 10 PAHs, exhibiting approximately monomodal distributions with the mode around or smaller than $0.5 \mu \mathrm{m}$. The PAHs with 4 rings composed $28 \%$ of the total PAHs in mass and showed bimodal distributions with one mode in the range of $<0.5 \mu \mathrm{m}$ and another in the range of $>1.0 \mu \mathrm{m}$. The estimate of BaPE using the 5- and 6-ring PAHs indicated that PAHs in particles $<2.1 \mu \mathrm{m}$ accounted for approximately $80 \%$ of the equivalents, suggesting that the carcinogenic potential of the PAHs was dominated by small particles. BaP together with BbF, DahA, and IcdP predominated in the equivalents, while the equivalents due to $\mathrm{BaA}$ and $\mathrm{BkF}$ were very small in all size ranges.
\end{abstract}

Key words — particulate polycyclic aromatic hydrocarbon, size, carcinogenic potential

\section{INTRODUCTION}

Polycyclic aromatic hydrocarbons (PAHs) are a complex class of organic compounds containing 2 or more fused aromatic rings. They are mainly composed of carbon and hydrogen and have potent carcinogenicity and strong mutagenicity. Incomplete biomass burning and fossil fuel combustion are their major sources. ${ }^{1-4)}$ Their concentrations in the urban atmosphere are usually much higher than in suburban and remote areas due to concentrated traffic and cooking emissions. ${ }^{5)}$ The health effects of PAHs in urban areas thus have become a public concern.

The smallest member of the PAH family is naphthalene, a 2-ring PAH in gas phase detected

*To whom correspondence should be addressed: Faculty of Environmental and Symbiotic Sciences, Prefectural University of Kumamoto, Tsukide 3-1-100, Kumamoto 862-8502, Japan. Tel.: +81-96-383-2929 (Ext.761); Fax: +81-96-384-6765; E-mail: zdz@ pu-kumamoto.ac.jp frequently in the atmosphere. PAHs with 3, 4, and 5 rings are in gas, liquid, or solid phases and those with more rings are usually in solid phase under normal atmospheric conditions. Liquid and solid PAHs appear in particles frequently mixing or not mixing with other matter, which can be inhaled into the human body and deposited. There is evidence showing a relationship between atmospheric particulate matters and diseases of the respiratory organs. ${ }^{6)}$ Particles of different sizes have different fates in the atmosphere, and in consequence particulate PAHs in different size ranges are expected to show different mutagenic and carcinogenic activity. In particular, information on the distribution of particulate PAHs by size is important for the assessment of health effects because the deposition behavior of particles in respiratory organs is closely dependent on particle size.

Primary emissions of PAHs usually produce a mode smaller than $0.1 \mu \mathrm{m}$ (called ultrafine mode), and the coalescence and coagulation of PAHs in 
this mode can produce an accumulation mode between $0.5-1.0$ or $2.0 \mu \mathrm{m}$ with the depletion of reactive PAHs in the smaller size ranges. A coarse mode around several micrometers was also found for PAHs with smaller molecular weights in the urban atmosphere, which was attributed to the accumulation of PAHs on primary coarse particles. ${ }^{7,8)}$

However, due to their high volatility and mutagenicity, it is very difficult to obtain a common understanding of particulate PAHs corresponding to their distribution and carcinogenic potential based upon size, although a few studies have been conducted in limited areas of Japan. ${ }^{7,9-11)}$ The purposes of this study are to characterize the size distribution of PAHs with 4-6 rings and their carcinogenic potential in different size ranges in the urban atmosphere of Kumamoto and to gain an insight into PAHs and their threat to human health in the nonmetropolitan urban atmosphere in Japan.

\section{MATERIALS AND METHODS}

Particle Collection - Size-fractioned aerosol samples were obtained with a cascade impactor (AN-200, Tokyo Dylec Inc., Tokyo, Japan) at a roadside site in the downtown area of Kumamoto in April and May 2006. The site is located on the pavement near a main road in the center of the city (Suidoucho Intersection of National Road 3: $\left.32^{\circ} 48^{\prime} 16^{\prime \prime} \mathrm{N}, 130^{\circ} 442^{\prime} 50^{\prime \prime} \mathrm{E}\right)$. The sampler was fixed at about $3 \mathrm{~m}$ from the road at a height of $1.5 \mathrm{~m}$ above the ground. At this site, strong influences from traffic were anticipated. The impactor consists of eight stages with $50 \%$ cutoff aerodynamic diameters $(\mathrm{Dp})$ of 11.0, 7.0, 4.7, 3.3, 2.1,
$1.1,0.65$, and $0.43 \mu \mathrm{m}$, and a backup filter stage for particles $<0.43 \mu \mathrm{m}$, at the flow rate $28.3 \mathrm{l} / \mathrm{min}$. Consequently, nine sample filters with approximate particle size ranges of $>11.0,11.0-7.0,7.0-4.7$, $4.7-3.3,3.3-2.1,2.1-1.1,1.1-0.65,0.65-0.43$, and $<0.43 \mu \mathrm{m}$ were available in each sample set. To describe the concentrations as $\mathrm{dC} / \mathrm{d} \log \mathrm{Dp}$ in the size ranges $>11.0 \mu \mathrm{m}$ and $<0.43 \mu \mathrm{m}$ in data analysis, the upper and lower particle size limits were set at $30 \mu \mathrm{m}$ and $0.05 \mu \mathrm{m}$, respectively, according to previous observational results. ${ }^{12,13)}$

Particles were collected onto T60A20 filters (80-mm diameter; Pallflex Products Corp., Tokyo Dylec Inc., Tokyo, Japan). The filters were developed for qualitative and quantitative analysis of organic carbon in atmospheric particulate matters. The advantage of the filters is their extremely low hygroscopicity. The collection time for one set of samples was not preset but within $24 \mathrm{hr}$. The collection was stopped and filters were removed instantly when it was going to rain. The collection was restarted with new filters after the rain stopped. Each filter was sealed in an individual holder after particle collection, and the holders were then preserved in a freezer at $-30^{\circ} \mathrm{C}$ until subsequent analyses. Filter blanks were also treated in the same manner as the sampling filter to ensure the confidence of the analysis results.

Twenty-nine sets of samples were obtained from April 21 to May 12. In the analysis, one or more sets of samples consecutively collected were combined to prepare a sample set for analysis to ensure the amount of detectable PAHs. Analyzed sample sets were actually from nine periods with raining time extracted. The periods, relevant weather information, and numbers of collected sample sets in each

Table 1. Particle Collection Periods for the Nine Analyzed Sets of Samples, Weather Conditions, and Other Relevant Information

\begin{tabular}{|c|c|c|c|c|c|c|c|}
\hline $\begin{array}{l}\text { Analyzed } \\
\text { set no. }\end{array}$ & $\begin{array}{c}\text { Sampling period } \\
\text { (Japanese Standard Time) }\end{array}$ & $\begin{array}{c}\text { Pressure } \\
\text { mean (range) } \\
(\mathrm{hPa})\end{array}$ & $\begin{array}{c}\text { Temperature } \\
\text { mean (range) } \\
\left({ }^{\circ} \mathrm{C}\right)\end{array}$ & $\begin{array}{c}\mathrm{RH} \\
\text { mean (range) } \\
(\%)\end{array}$ & $\begin{array}{c}\text { No. of } \\
\text { sample } \\
\text { sets }\end{array}$ & $\begin{array}{l}\text { C.S.T. }^{a)} \\
\quad(\mathrm{hr})\end{array}$ & Remarks \\
\hline 1 & 13:30 April 21 -11:00 April 23 & $1004(1002-1006)$ & $13 \quad(9-20)$ & $73(54-86)$ & 3 & 45 & Rain \\
\hline 2 & 11:15 April 23-13:10 April 25 & $1007(1003-1010)$ & $15(6-21)$ & $60(49-80)$ & 4 & 50 & \\
\hline 3 & 13:20 April 25-11:05 April 26 & 1009 (1010-1007) & $14(6-21)$ & $59(50-68)$ & 2 & 22 & \\
\hline 4 & 11:18 April 26-14:02 April 27 & $1007(1007-1010)$ & $15(11-22)$ & $67(65-68)$ & 2 & 26 & \\
\hline 5 & 14:13 April 27-17:57 April 29 & $1006(1004-1008)$ & $17(10-24)$ & $58(49-65)$ & 3 & 51 & \\
\hline 6 & 18:09 April 29-16:45 April 30 & 1005 (1004-1006) & $19(10-24)$ & $62(60-63)$ & 1 & 23 & \\
\hline 7 & 13:50 May 3-16:40 May 7 & $1011(1004-1016)$ & $20(13-28)$ & $63(45-88)$ & 6 & 59 & Rain \\
\hline 8 & 16:52 May 7-13:36 May 9 & 1007 (1004-1014) & $21(15-29)$ & $79(74-88)$ & 4 & 45 & \\
\hline 9 & 13:45 May 9-16:40 May 12 & $1010(1007-1012)$ & $22(18-29)$ & $74(61-88)$ & 4 & 52 & Rain \\
\hline
\end{tabular}

a) C.S.T.: cumulative sampling time. 
period are summarized in Table 1.

PAH Analysis — Sixteen PAHs with 2-6 rings specified in the US Environmental Protection Agency list were analyzed. Six are 2- and 3-ring PAHs, which are very volatile and appear partly in gas phase in the atmosphere. It is likely that the results of their distributions by size had very large uncertainties because of their probable evaporation and redeposition on different stage filters during particle impaction. For this reason, they are excluded from the following descriptions and discussion. The remaining 10 PAHs, which had 4, 5, or 6 rings, included fluoranthene (Flu), pyrene (Pyr), benz(a)anthracene (BaA), chrysene (Chry), benzo(b)fluoranthene (BbF), benzo(a)pyrene $(\mathrm{BaP})$, benzo(k)fluoranthene $(\mathrm{BkF})$, dibenz(a,h)anthracene (DahA), benzo(ghi)perylene (BghiP), and indeno(1,2,3,-cd)pyrene (IcdP). Field measurements have shown that 4-ring PAHs (Flu, Pyr, BaA, Chry) partition to varying extents into gas phase at temperatures around $25^{\circ} \mathrm{C}$, and the 5- and 6-ring PAHs (BaF, BaP, BkF, DahA, BghiP, IcdP) are present almost entirely in particulate phase at such temperatures. ${ }^{14)}$ The particulate PAHs with 4, 5 and 6 rings collected on the stages can thus, to a large extent, represent their mass partitioning in each size range because the temperature during particle collection was usually much lower than $25^{\circ} \mathrm{C}$ (Table 1).

The extraction of PAHs from the filters using an accelerated solvent extractor and the analysis of PAHs using GC-MS were almost the same as reported by $\mathrm{Ji}$ et al., ${ }^{15}$ ) which was based on the method suggested by Sienra et al. ${ }^{16)}$ Here, analysis procedures are briefly described according to the operation order: Each filter was cut into small pieces and the pieces were put into a stoppered centrifuge; Surrogates were added for estimating the recovery efficiency; Organic compounds were extracted three times using an ultrasonic generator, each for $30 \mathrm{~min}$ with $50 \mathrm{ml}$ of dichloromethane (DCM); Extraction solutions were filtered and condensed to about $1 \mathrm{ml}$ with a Kuderna-Danish concentrator; Interfering compounds were removed by solid-phase extraction with silica gel. The column packed with silica gel was washed with $20 \mathrm{ml}$ of hexane; The concentrated solution was injected into the column to trap PAHs on silica gel; Eight milliliters of hexane was applied to remove aliphatic hydrocarbons. In case of the appearance of PAHs in the aliphatic hydrocarbon-hexane solution, the solution was put into the column again, and this was re- peated until no PAH was detectable in the solution; Ten milliliters of DCM-hexane $(1: 1)$ was added to the column to elute PAHs; One milliliter of benzene was added to the PAHs-dissolving solution and then the solution was concentrated to about $1 \mathrm{ml}$ with a Kuderna-Danish concentrator; The concentrated solution was further coagulated with a gentle stream of nitrogen to approximately $0.5 \mathrm{ml}$; and Before GCMS analysis, the internal standard Chrysene-d12 (Ultra Scientific Inc., N. Kingstown, RI, U.S.A.) was added to ready the sample solution for analysis.

Recovery tests of the PAHs from the analysis of calibration solutions were carried out three times using the method described above. PAHs from Sigma-Aldrich Laborchemikalien GMBH (Seelze, Germany) were applied to prepare the calibration solution for the recovery tests. The tests were carried out at the PAH concentrations of 30, 40, and $50 \mathrm{ppb}$, respectively. The average recovery rates for the standard reference materials of the $10 \mathrm{PAHs}$ were $84.8-102.4 \%$. Details were described by Ji et $a l .,{ }^{15}$ and for reference the recovery rates and detection limits corresponding to each of the 10 PAHs are shown in Appendix Table 1.

BaP- $d_{12}$ and Pyr- $d_{10}$ were used as surrogates for PAHs in the sample analysis in a solution of $4 \mu \mathrm{l}$ each at a concentration of $10 \mathrm{ppm}$ in acetone solvent in each analysis. Their recovery rates were $92 \pm 9.2 \%$ with variance of $4.6-16.5 \%$ in the PAH analysis. PAH concentrations were calibrated with the relevant recovery rates in each analysis.

\section{RESULTS AND DISCUSSION}

\section{Mass of the 10 PAHs}

The total concentrations of the 10 PAHs ( $\sum$ PAH10) in the nine periods ranged from 7.88 to $30.64 \mathrm{ng} / \mathrm{m}^{3}$ (average $15.97 \mathrm{ng} / \mathrm{m}^{3}$ ), which is comparable to that in Kitakyushu and Tokyo, Japan, ${ }^{17}$ but much less than that in Beijing and Guangzhou, China $^{5,18)}$ and Ho Chi Minh City, Vietnam. ${ }^{8)} \mathrm{BbF}$ and IcdP were the two major contributors and accounted for about $44 \%$ of the $\sum$ PAH10 value, followed by BghiP (14\%), Pyr (11\%), BaP (9\%), and Flu (9\%). Others (DahA, BkF, Chry, BaA) accounted for approximately $13 \%$. In total, the 4-ring PAHs (Pyr, Flu, BaA, Chry) contributed about 28\% of the $\sum$ PAH10 value and the 5- and 6-ring PAHs (BbF, BkF, BaP, BghiP, DahA, IcdP) contributed about $72 \%$. Details of the contributions of the PAHs 
Table 2. Ratios (\%) of Each PAH to the $\sum$ PAH10 in Each Analyzed Set of Samples, Their Average and Deviation (Ave \pm Dev), and the Sum of the 10 PAHs ( $\sum$ PAH10) of Each Set in Unit $\mathrm{ng} / \mathrm{m}^{3}$

\begin{tabular}{cccccccccccc}
\hline \hline Set No. & Flu & Pyr & BaA & Chry & BbF & BkF & BaP & BghiP & DahA & IcdP & $\sum$ PAH10 \\
\hline 1 & 6.2 & 7.4 & 1.6 & 1.6 & 20.8 & 3.9 & 6.0 & 19.9 & 1.9 & 30.7 & 18.58 \\
2 & 7.7 & 9.5 & 2.1 & 3.9 & 25.6 & 5.2 & 8.7 & 15.8 & 0.9 & 20.7 & 9.76 \\
3 & 12.7 & 14.3 & 1.5 & 4.2 & 21.2 & 2.4 & 8.2 & 13.4 & 2.4 & 19.7 & 16.89 \\
4 & 10.6 & 9.7 & 2.9 & 2.7 & 23.1 & 4.2 & 10.6 & 14.1 & 1.2 & 20.9 & 16.70 \\
5 & 8.2 & 9.1 & 2.7 & 10.1 & 23.2 & 2.4 & 9.9 & 13.7 & 1.2 & 19.4 & 30.64 \\
6 & 10.7 & 11.2 & 1.9 & 1.9 & 25.1 & 4.4 & 9.6 & 12.8 & 1.9 & 20.6 & 12.88 \\
7 & 6.8 & 6.3 & 7.2 & 3.2 & 24.7 & 2.4 & 7.6 & 15.1 & 2.8 & 23.8 & 7.88 \\
8 & 10.3 & 13.1 & 3.4 & 2.9 & 22.6 & 5.5 & 4.7 & 12.5 & 3.6 & 21.4 & 13.59 \\
9 & 8.5 & 14.5 & 2.3 & 3.5 & 20.0 & 2.2 & 16.5 & 8.7 & 2.1 & 21.6 & 16.83 \\
Ave \pm Dev & $9.1 \pm 2.0$ & $10.9 \pm 2.8$ & $2.6 \pm 1.7$ & $4.6 \pm 2.4$ & $22.5 \pm 1.9$ & $3.5 \pm 1.2$ & $9.2 \pm 3.1$ & $14.0 \pm 2.8$ & $1.9 \pm 0.8$ & $21.7 \pm 3.3$ & $15.97^{a)}$ \\
\hline
\end{tabular}

a) Average of $\sum$ PAH10.

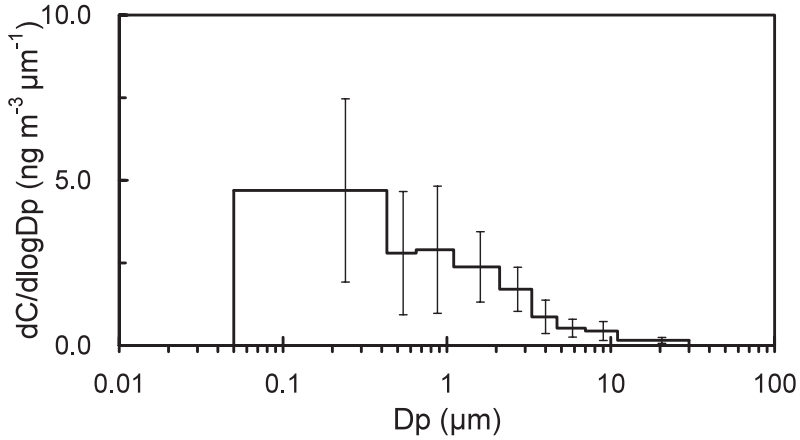

Fig. 1. Distribution of the $\sum P A H 10$ by Particle Size and Standard Deviations

and the $\sum$ PAH10 values are listed in Table 2.

Figure 1 shows the mass-size distribution of the $\sum$ PAH10 values. For reference, the average concentrations of each PAH and their ranges in each size range from the nine analyzed sets of samples are shown in Appendix Table 2. It is clear that the PAHs tended to accumulate in small size ranges, which is consistent with the current understanding of the mass-size distribution of particulate PAHs in the urban atmosphere. In particular, PAHs concentrated in particles smaller than $2.1 \mu \mathrm{m}$, which is the approximate upper critical size for particles easily inhaled deep into human respiratory systems with a noticeable risk to health. The PAHs in particles $<2.1 \mu \mathrm{m}$ composed more than $78 \%$ of the $\sum$ PAH10, while those in particles $>2.1 \mu \mathrm{m}$ constituted less than $22 \%$ in mass, i.e., the mass ratio of the PAHs in the size range $<2.1 \mu \mathrm{m}$ to that in the range $>2.1 \mu \mathrm{m}$ was about 4.

\section{Distribution of 4-ring PAHs}

Figure 2 shows the distributions of 4-ring PAHs. Except for the smallest contributor $\mathrm{BaA}$ to the

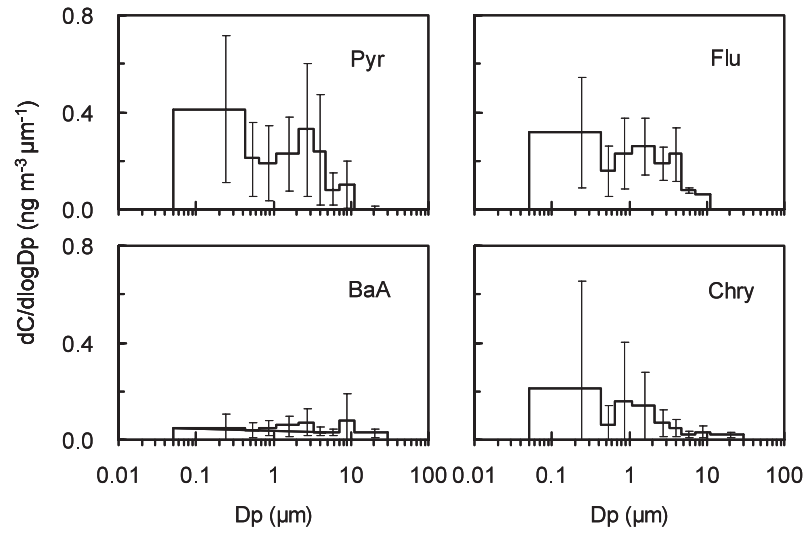

Fig. 2. Distributions of 4-ring PAHs by Particle Size and Standard Deviations

$\sum$ PAH10 value, the other three 4-ring PAHs (Pyr, Flu, Chry) showed bimodal distributions: one mode in the range smaller than $0.5 \mu \mathrm{m}$ and another in the range around or larger than $1.0 \mu \mathrm{m}$. The mode smaller than $0.5 \mu \mathrm{m}$ was the result of primary emission from vehicles because the site was only $3 \mathrm{~m}$ away from a main road and pollutants from traffic could reach the site within several seconds after being emitted into the air. Direct measurements of PAHs in diesel and gasoline engine emissions have confirmed that the primary emissions are responsible for the mode smaller than $0.5 \mu \mathrm{m} .{ }^{19)}$

Several processes could result in the accumulation of PAHs in the mode around or larger than $1.0 \mu \mathrm{m}$. It has been suggested that primary PAHcontaining particles in ultrafine mode $(<0.1 \mu \mathrm{m})$ could expand by coalescence with other fine particles. However, this process can only produce an accumulation mode of around $0.5 \mu \mathrm{m}$, which has been observed in many urban and suburban sites. Similar accumulation modes were not observed in this 
study, suggesting that most of the collected PAHs did not undergo aging transformation in the atmosphere. This is reasonable because the site was very close to the road, while the transfer process is usually slow.

One probable reason for the modes larger than $1.0 \mu \mathrm{m}$ is that a small part of primary particles was trapped onto stages for larger particles. This is because traffic such as heavy trucks with diesel engines, in addition to ultrafine particles, can also emit particles as aggregates of soot chains and ultrafine spheres, of which the sizes are frequently larger than $1.0 \mu \mathrm{m} .{ }^{13)}$ Another reason is likely the resuspension of road dust by vehicles. Dry deposition of PAHs around the observation site could cause their gradual accumulation on surface soil particles. Measurements of road dust in Beijing showed that the average abundance of organic carbons attributed to traffic emissions in road dust was about $11.5 \% .^{20)}$

\section{Distribution of 5- and 6-ring PAHs}

Figure 3 shows the distributions of 5- and 6-ring PAHs. The distribution of the $\sum$ PAH10 were dominated by $\mathrm{BbF}$ and IcdP from the comparisons of Figs. 1, 2, and 3. This is consistent with the results that $\mathrm{BbF}$ and IcdP were the largest two PAHs among the 10 PAHs in mass (Table 2). In contrast to 4-ring PAHs that had bimodal distributions, the 5- and 6ring PAHs showed approximate monomodal distributions with the modes in the range around $(\mathrm{BaP}$, $\mathrm{BkF})$ or smaller than (BbF, DahA, BghiP, IcdP)

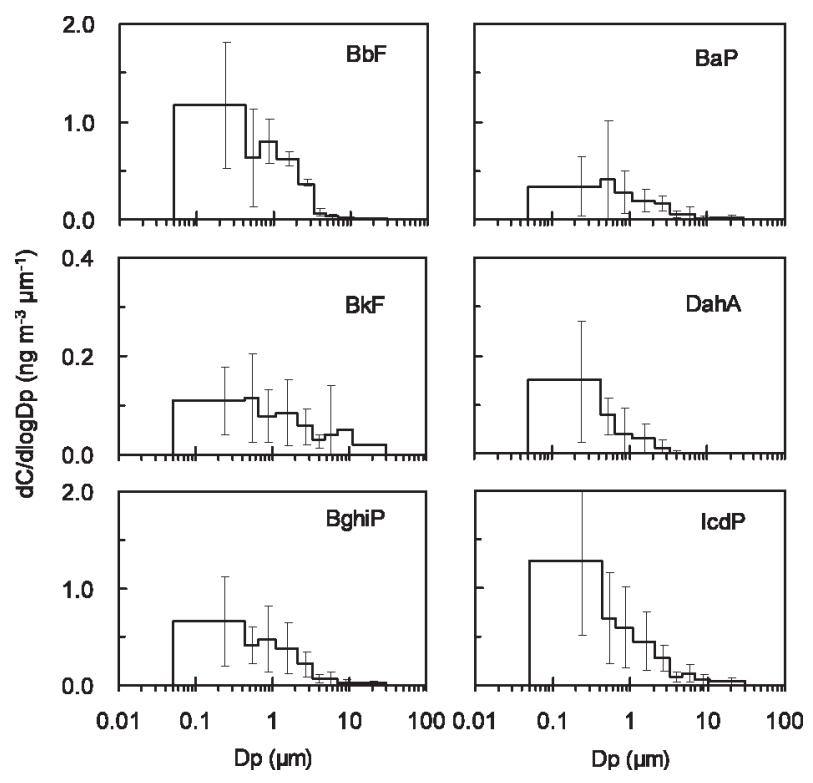

Fig. 3. Distributions of 5- and 6-ring PAHs by Particle Size and Standard Deviations
$0.5 \mu \mathrm{m}$, although their concentration at 2 or $3 \mu \mathrm{m}$ was not negligible. BkF had another mode at about $9.0 \mu \mathrm{m}$, but the concentrations of BkF were very small and the mode around $9.0 \mu \mathrm{m}$ could even be considered as noise because of its small concentration and large variance. The 5- and 6-ring PAHs are nonvolatile and tend to remain in fine particle modes, which were frequently reported in previous studies.

\section{Carcinogenic Potential of PAHs Evaluated with the Equivalent of Benzo(a)pyrene (BaPE)}

$B a P E$ is an index proposed to parameterize the carcinogenic potential of PAHs in atmospheric particulate matter for comparative purposes. The $B a P E$ value is calculated with PAH concentrations weighted in relation to the carcinogenic potential of individual PAHs. ${ }^{21)}$ Benzo(a)pyrene-equivalent species include $\mathrm{BaA}, \mathrm{BbF}, \mathrm{BkF}$, DahA, BaP, and IcdP, and $B a P E$ is defined as:

$$
\begin{aligned}
B a P E= & 0.06[\mathrm{BaA}]+0.07[\mathrm{BbF}]+0.07[\mathrm{BkF}] \\
& +[\mathrm{BaP}]+0.6[\mathrm{DahA}]+0.08[\mathrm{IcdP}]
\end{aligned}
$$

in which PAHs enclosed in brackets refer to their mass concentrations.

The coefficient of each item represents the carcinogenic potential of the PAH relative to that of BaP. BaPE rather than $\mathrm{BaP}$ is applied to demonstrate the carcinogenic potential of PAHs because of the limited number of PAHs for which pure standard materials are available and the limited number of PAH compounds certified in reference materials produced to date. ${ }^{22)}$

Because of its predominant carcinogenic potential, $\mathrm{BaP}$ dominated the $B a P E$ in all size ranges and it accounted for approximately $62 \%$ of the total

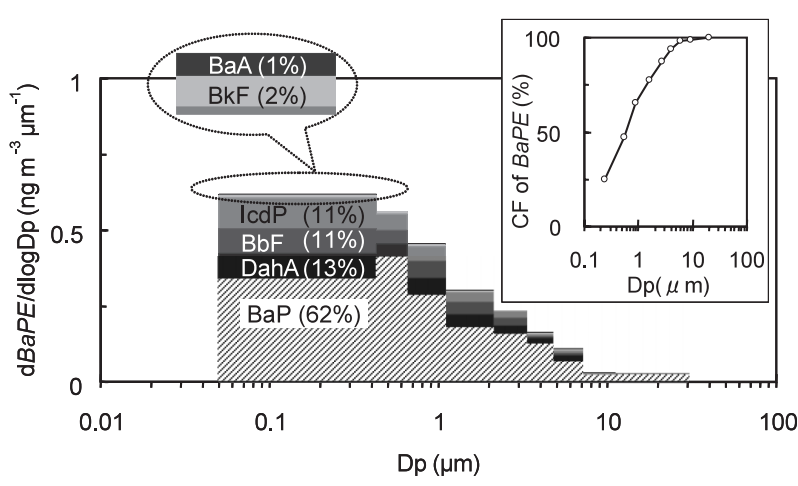

Fig. 4. Distribution of the $B a P E$ by Particle Size with the Relative Contributions of Each PAH to the $B a P E$ in Parentheses, and the Cumulative Fractions (CF) of the $B a P E$ by the Size in the Inset Panel 
equivalents. BbF, DahA, and IcdP made some contribution, particularly in the size range of $<2.1 \mu \mathrm{m}$, where their mass concentrations were larger than that of $\mathrm{BaP}$ (Fig. 4). The equivalents due to $\mathrm{BaA}$ and BkF were very small compared to other PAHs in all size ranges. On average, approximately $80 \%$ of the carcinogenic potential was due to the PAHs in particles $<2.1 \mu \mathrm{m}$, and in contrast PAHs in particles $>2.1 \mu \mathrm{m}$ had much less potential.

Health effects related to atmospheric particles are size dependent. Particles $<2.5 \mu \mathrm{m}$ are easily inhaled deep into the human respiratory system and deposited onto the respiratory tract and pulmonary alveolus. ${ }^{11)}$ From this point of view, the particulate PAHs emitted from traffic in the central areas of Kumamoto have significant potential to threaten the health of inhabitants because of their accumulation in the size range smaller than $2.1 \mu \mathrm{m}$.

Acknowledgements We thank Mr. K. Ueno, director of the Atmospheric Section of the Kumamoto Prefectural Institute of Public-Health and Environmental Science for his assistance with sample collection. The observation was supported by the Foundation for Local Research of Kumamoto. Financial support was partly provided by the Japan Society for the Promotion of Science. The authors thank the two anonymous reviewers for their comments and suggestions.

Appendix Appendix Table 1, Appendix Table 2.

Appendix Table 1. Average Recovery Rates (REC) with Their Ranges Identified Using Calibration Solution, Detection Limits (DL), and Quantification Limits (QL) of the 10 PAHs [from Data in Reference 15]

\begin{tabular}{lrcc}
\hline \hline PAHs & REC (range) $(\%)$ & DL $\left(\mathrm{ng} / \mathrm{m}^{3}\right)$ & QL $\left(\mathrm{ng} / \mathrm{m}^{3}\right)$ \\
\hline Fluoranthene (Flu) & $84.8(70.7-103.2)$ & 0.0004 & 0.0015 \\
Pyrene (Pyr) & $88.0(77.8-99.7)$ & 0.0007 & 0.0024 \\
Benz(a)anthracene (BaA) & $99.3(82.2-114.9)$ & 0.0009 & 0.0030 \\
Chrysene (Chry) & $87.1(73.8-100.1)$ & 0.0004 & 0.0012 \\
Benzo(b)fluoranthene (BbF) & $87.3(81.0-90.7)$ & 0.0006 & 0.0020 \\
Benzo(k)fluoranthene (BkF) & $102.4(79.7-146.3)$ & 0.0011 & 0.0064 \\
Benzo(a)pyrene (BaP) & $92.4(75.3-119.9)$ & 0.0007 & 0.0025 \\
Benzo(ghi)perylene (BghiP) & $96.4(90.7-100.8)$ & 0.0080 & 0.0014 \\
Dibenz(a,h)anthracene (DahA) & $93.1(86.1-103.3)$ & 0.0007 & 0.0025 \\
Indeno(1,2,3-cd)pyrene (IcdP) & $93.7(89.2-102.4)$ & 0.0003 & 0.0010 \\
\hline
\end{tabular}

Appendix Table 2. Average Concentrations and Their Ranges of Each PAH in Different Size Ranges from the Analyzed Nine Sets of Samples

\begin{tabular}{lccccc}
\hline \hline PAHs & \multicolumn{5}{c}{ Size range $(\mu \mathrm{m})$} \\
\cline { 2 - 6 } & $<0.43$ & $0.43-0.65$ & $0.65-1.1$ & $1.1-2.1$ & $2.1-3.3$ \\
\hline Flu & $0.06(0.03-0.73)$ & $0.15(0.03-0.34)$ & $0.26(0.06-0.47)$ & $0.22(0.03-0.64)$ & $0.06(0.02-0.35)$ \\
Pyr & $0.05(0.03-0.91)$ & $0.15(0.03-0.59)$ & $0.30(\mathrm{BDL}-0.43)$ & $0.23(0.03-0.54)$ & $0.05(0.02-0.90)$ \\
BaA & $0.05(0.02-0.20)$ & $0.02(0.01-0.11)$ & $0.03(0.01-0.10)$ & $0.02(0.01-0.15)$ & $0.02(0.02-0.19)$ \\
Chry & $0.05(0.02-1.46)$ & $0.02(0.01-0.21)$ & $0.02(0.01-0.72)$ & $0.03(0.01-0.48)$ & $0.02(0.01-0.17)$ \\
BbF & $1.17(0.66-2.73)$ & $0.63(0.05-1.23)$ & $0.80(0.26-1.6)$ & $0.57(0.04-1.14)$ & $0.37(0.00-0.89)$ \\
BkF & $0.11(0.03-0.26)$ & $0.11(0.03-0.29)$ & $0.08(0.02-0.17)$ & $0.07(0.02-0.25)$ & $0.05(0.02-0.14)$ \\
BaP & $0.33(0.01-1.13)$ & $0.41(0.01-0.51)$ & $0.28(0.04-0.73)$ & $0.17(0.02-0.38)$ & $0.15(0.08-0.31)$ \\
BghiP & $0.66(0.12-1.45)$ & $0.41(0.11-0.79)$ & $0.47(0.07-1.05)$ & $0.33(0.07-0.9)$ & $0.18(0.07-0.50)$ \\
DahA & $0.15(0.02-0.38)$ & $0.08(0.04-0.17)$ & $0.10(\mathrm{BDL}-0.17)$ & $0.08(\mathrm{BDL}-0.11)$ & $0.05(\mathrm{BDL}-0.08)$ \\
IcdP & $1.28(0.30-2.64)$ & $0.69(0.44-1.87)$ & $0.59(0.09-1.27)$ & $0.39(0.07-1.04)$ & $0.25(0.10-0.58)$ \\
$\sum_{\mathrm{B}}$ & $3.91(1.24-11.89)$ & $2.67(0.76-6.11)$ & $2.94(0.56-6.71)$ & $2.10(0.30-5.60)$ & $1.20(0.34-4.07)$ \\
\hline
\end{tabular}

$\sum_{\mathrm{A}}$ shows the average concentrations and their ranges of each PAH accumulated in the whole size range. $\sum_{\mathrm{B}}$ shows the average concentrations and their ranges of the accumulation of the $10 \mathrm{PAHs}$ in each size range. The data are shown in the format of [average (range)] in the unit ng/ $\mathrm{m}^{3}$. BDL, below detection limit. 
Appendix Table 2. (Continued)

\begin{tabular}{lccccc}
\hline \hline \multirow{2}{*}{ PAHs } & \multicolumn{4}{c}{ Size range $(\mu \mathrm{m})$} & $\sum_{\mathrm{A}}$ \\
\cline { 2 - 5 } & $3.3-4.7$ & $4.7-7.0$ & $7.0-11.0$ & $>11.0$ \\
\hline Flu & $0.23(0.04-0.78)$ & $0.18(0.02-0.19)$ & $0.14(\mathrm{BDL}-0.37)$ & $0.02(\mathrm{BDL}-0.03)$ & $1.32(0.23-3.90)$ \\
Pyr & $0.25(0.04-0.83)$ & $0.17(0.01-0.19)$ & $0.17(\mathrm{BDL}-0.32)$ & $0.03(\mathrm{BDL}-0.02)$ & $1.39(0.16-4.73)$ \\
BaA & $0.08(0.01-0.08)$ & $0.02(0.01-0.05)$ & $0.04(\mathrm{BDL}-0.38)$ & $0.02(\mathrm{BDL}-0.06)$ & $0.29(0.09-1.32)$ \\
Chry & $0.09(0.01-0.12)$ & $0.02(0.01-0.05)$ & $0.03(0.01-0.08)$ & $0.02(0.01-0.05)$ & $0.29(0.10-3.34)$ \\
BbF & $0.09(0.00-0.20)$ & $0.10(0.00-0.10)$ & $0.02(0.00-0.10)$ & $0.01(\mathrm{BDL}-0.08)$ & $3.75(1.01-8.07)$ \\
BkF & $0.03(0.01-0.06)$ & $0.04(0.01-0.13)$ & $0.05(\mathrm{BDL}-0.34)$ & $0.02(\mathrm{BDL}-0.06)$ & $0.55(0.14-1.70)$ \\
BaP & $0.12(\mathrm{BDL}-0.14)$ & $0.06(\mathrm{BDL}-0.23)$ & $0.01(\mathrm{BDL}-0.06)$ & $0.02(\mathrm{BDL}-0.07)$ & $1.55(0.32-7.12)$ \\
BghiP & $0.08(\mathrm{BDL}-0.15)$ & $0.10(\mathrm{BDL}-0.19)$ & $0.02(\mathrm{BDL}-0.08)$ & $0.02(\mathrm{BDL}-0.06)$ & $2.27(0.44-5.17)$ \\
DahA & $0.04(\mathrm{BDL}-0.06)$ & $0.04(\mathrm{BDL}-0.04)$ & BDL & BDL & $0.54(0.06-0.85)$ \\
IcdP & $0.09(0.02-0.19)$ & $0.13(0.00-0.27)$ & $0.06(0.00-0.14)$ & $0.04(\mathrm{BDL}-0.10)$ & $3.51(1.02-8.09)$ \\
$\sum_{\mathrm{B}}$ & $1.07(0.13-2.55)$ & $0.84(0.06-1.40)$ & $0.55(0.01-1.87)$ & $0.18(0.01-0.53)$ & \\
\hline
\end{tabular}

\section{REFERENCES}

1) Baek, S. O., Field, R. A., Goldstone, M. E., Kirk, P. W., Lester, J. N. and Perry, R. (1991) A review of atmospheric polycyclic aromatic hydrocarbons: Sources, fate and behavior. Water Air Soil Pollut., 60, 279-300.

2) Seinfeld, J. H. and Pandis, S. N. (1998) Atmospheric Chemistry and Physics, John Wiley and Sons, New York, pp. 700-764.

3) Watson, A. Y., Bates, R. R. and Kennedy, D. (1988) Air Pollution, the Automobile, and Public Health, National Academy Press, Washington D. C., pp. 3976.

4) Yang, S. Y., Connell, N., Hawker, D. W. and Kayal, S. I. (1991) Polycyclic aromatic hydrocarbons in air, soil and vegetation in the vicinity of an urban roadway. Sci. Total Environ., 102, 229-240.

5) Zhou, J., Wang, T., Huang, Y., Mao, T. and Zhong, N. (2005) Size distribution of polycyclic aromatic hydrocarbons in urban and suburban sites of Beijing, China. Chemosphere, 61, 792-799.

6) U.S. Department of Health and Human Services (1995) Agency for Toxic Substances and Disease Registry (ATSDR) August, Toxicological Profile for Polycyclic Aromatic Hydrocarbons, pp. 11-64.

7) Kawanaka, Y., Matsumoto, E., Sakamoto, K., Wang, N. and Yun, S. J. (2004) Size distributions of mutagenic compounds and mutagenicity in atmospheric matters collected with a low-pressure cascade impactor. Atmos. Environ., 38, 2125-2132.

8) Hien, T. T., Thanh, L. T., Kameda, T., Takenaka, N. and Bandow, H. (2007) Distribution characteristics of polycyclic aromatic hydrocarbons with particle size in urban aerosols at the roadside in Ho Chi Minh City, Vietnam. Atmos. Environ., 41, 1575-1586.

9) Kawanaka, Y. Wang, N., Yun, S. J. and Sakamoto,
K. (2002) Size distributions and seasonal variations: concentrations of 1-nitropyrene and polycyclic aromatic hydrocarbons in atmospheric particulate matter. J. Environ. Chem., 12, 599-607 (in Japanese).

10) Yamaguchi, T., Yamasaki, C. and Yamazaki, H. (2004) Characteristics of size-classified airborne particulates in Kobe, Japan. J. Health Sci., 50, 290295.

11) Kameda, Y., Shirai, J., Komai, T., Nakanishi, J. and Masunaga, S. (2005) Atmospheric polycyclic aromatic hydrocarbons: size distribution, estimation of their risk and their depositions to the human respiratory tract. Sci. Total Environ., 340, 71-80.

12) Lundgren, D. A., Hausknecht, B. J. and Burton, R. M. (1984) Large particle size distribution in five US cities and the effect on a new ambient particulate matter standard $\left(\mathrm{PM}_{10}\right)$. Aeros. Sci. Technol., 3, 467-473.

13) Venkataraman, C. and Friedlander, S. K. (1994) Size distributions of polycyclic aromatic hydrocarbons and elemental carbon. 2. Ambient measurements and effects of atmospheric processes. Environ. Sci. Technol., 28, 563-572.

14) Yamasaki, H., Kuwata, K. and Miyamoto, H. (1982) Effects of ambient temperature on aspects of airborne polycyclic aromatic hydrocarbons. Environ. Sci. Technol., 16, 189-194.

15) Ji, H., Zhang, D., Shinohara, R., Fujiie, W., Koga, M., Shi, Z. and Nomiyama, K. (2007) Particulate polycyclic aromatic hydrocarbons in the urban atmosphere of Kumamoto, Japan under mild weather. Earozoru Kenkyu, 22, 135-142.

16) Sienra, M. R., Rosazza, N. G. and Préndez, M. (2005) Polycyclic aromatic hydrocarbons and their molecular diagnostic ratios in urban atmospheric respirable particulate matter. Atmos. Res., 75, 267281. 
17) Tang, N., Hattori, T., Taga, R., Igarashi, K., Yang, X., Tamura, K., Kakimoto, H., Mishukov, V. F., Toriba, A., Kizu, R. and Hayasaka, K. (2005) Polycyclic aromatic hydrocarbons and nitropolycyclic aromatic hydrocarbons in urban air particulates and their relationship to emission sources in the PanJapan Sea countries. Atmos. Environ., 39, 58175826.

18) Li, C., Fu, J., Sheng, G., Bi, X., Hao, Y., Wang, X. and Mai, B. (2005) Vertical distribution of PAHs in the indoor and outdoor PM2.5 in Guangzhou, China. Build. Environ., 40, 329-341.

19) Zielinska, B., Sagebiel, J., Arnott, W. P., Rogers, C. F., Kelly, K. E., Wagner, D. A., Lighty, J. S., Sarofim, A. F. and Palmer, G. (2004) Phase and size distribution of polycyclic aromatic hydrocarbons in diesel and gasoline vehicle emissions. Environ. Sci. Technol., 38, 2557-2567.
20) Chen, J., Wang, W., Liu, H., Zheng, H., Lu, L., Wang, Z. and Liu, X. (2006) Road dust loadings and its source characteristics in Beijing. Proceedings of the International Workshop on Regional Ecology and Its Environmental Effect - Dust Sand Storm, Its Impact and Mitigation Countermeasure-, Dec. 35, Beijing, pp. 36-37.

21) Yassaa, N., Meklati, B. Y., Cecinato, A. and Marino, F. (2001) Particulate n-alkanes, n-alkanoic acids and polycyclic aromatic hydrocarbons in the atmosphere of Algiers city area. Atmos. Environ., 35, 1843 1851.

22) Law, R. J., Kelly, C., Baker, K., Jones, J., McIntosh, A. D. and Moffat, C. F. (2002) Toxic equivalency factors for PAH and their applicability in shellfish pollution monitoring studies. J. Environ. Monit., 4, 383-388. 